\title{
Malignant melanoma of the skin among workers in a telecommunications industry: a mortality study 1976-83
}

\author{
Louise DeGuire, Diane Cyr, Gilles Thériault, Simone Provencher, Hilda Iturra, Bruce W Case
}

\begin{abstract}
An incidence study of malignant melanoma of the skin (MMS), conducted previously among the workers of four plants of a large telecommunications industry located in Montreal, Canada, showed a standardised incidence ratio of 2.7 (95\% confidence interval $(95 \%$ CI) $1.3-$ $5.02)$ for the years 1976 to 1983 . To describe more precisely the magnitude of the problem a mortality study was started among the same population $(n=9590)$ for the same period (1976-83). At the end of 1983,9180 workers were alive, 261 were dead, and $149(1.5 \%)$ were not traced. Standardised mortality ratios (SMRs) for all causes of death were surprisingly low for men (SMR $=0.57 ; 95 \%$ CI $0.50-0.64)$ and women (SMR $=0.56 ; 95 \%$ CI $0.37-0.82)$. The SMRs for major causes of death were also less than expected. These results may be explained by a pronounced selection bias (healthy worker effect) and by the short duration of follow up (eight years). For MMS, two deaths occurred among men (SMR $=2 \cdot 00$; 95\% CI 0.24-7.22) and one among women $(\mathrm{SMR}=4.81 ; 95 \% \mathrm{CI}$ $0 \cdot 12-26 \cdot 78)$. A third man who died of MMS was miscoded as having a primary pulmonary melanoma. Including this case increased the SMR for MMS to 3.00 (95\% CI 0.62-8.77; $p=0.08)$. Polyvinyl chloride and polychlorinated biphenyls were used in the plants and some of the workers did soldering. A planned case-control study will investigate other possible exposures at work.
\end{abstract}

An incidence study of malignant melanoma of the skin (MMS) was previously conducted among the workers of a large telecommunications industry for

Department of Community Health, Sacre-Coeur Hospital, 5945 Gouin West, Suite 200, Montreal, Quebec, Canada

L DeGuire, S Provencher, H Iturra

School of Occupational Health, McGill University, Montreal, Canada

L DeGuire, D Cyr, G Thériault, B W Case the years 1976 to 1983 . Among men, 10 cases were found and the standardised incidence ratio (SIR) was $2 \cdot 7(95 \%$ confidence interval $(95 \% \mathrm{CI}) 1 \cdot 3-5 \cdot 02)$. No cases were found among female workers. ${ }^{1}$

During the same period, a second study was initiated. The objective was to estimate mortality from MMS among the workers of four plants of this same telecommunications industry located in Montreal, Canada, from 1976 to 1983.

In published reports, personal risk factors for MMS have included sun exposure, ${ }^{2}$ fair skin and hair and blue eyes, ${ }^{3}$ and naevi ${ }^{4}$; MMS was also more frequent in higher socioeconomic classes. ${ }^{5}$ With regard to occupation, MMS was more prevalent in white collar than in blue collar workers. ${ }^{6}$ Workers in occupations with exposure to sun showed an increased risk of developing $\mathrm{MMS}^{7}$ Excesses of MMS cases have been found with exposure to polyvinyl chloride (PVC) ${ }^{89}$ and polychlorinated biphenyls (PCBs). ${ }^{10}$ Gold miners, ${ }^{11}$ veterinarians, ${ }^{12}$ and chemists ${ }^{13}$ showed high risks for MMS. Work in a nuclear energy laboratory ${ }^{14}$ and an aircraft industry ${ }^{15}$ has also been associated with MMS.

\section{Material and methods}

The population under study consisted of male and female employees active on 1 January 1976 and new workers hired from the beginning of 1976 to 31 December 1983. Only those workers with six or more months of experience at the plants were eligible for the study.

For each employee, the contribution of personyears was computed using Monson's programme. ${ }^{16}$ The date of entry into the study was 1 January 1976 or the date of hire, if later. The end of the period of observation was 31 December 1983 for workers who were known alive, or date of death, or date lost to follow up, whichever was appropriate.

Expected numbers of deaths were calculated from the death rates of the population of the Montreal area for the same period. The denominators for these rates were extracted from the Census of Canada for 1976 and $1981 .{ }^{17-20}$ Numerators were secured from a provincial agency in charge of official vital statistics (Bureau de la Statistique du Quebec). 
Table 1 Standardised mortality ratios (SMRs) and 95\% CIs in a telecommunications industry 1976-1983; male workers

\begin{tabular}{|c|c|c|}
\hline Cause of death & $\begin{array}{l}\text { Observed } \\
\text { deaths }\end{array}$ & $S M R(95 \% C I)$ \\
\hline All (000-999) & 231 & $0.57(0.50-0.64)$ \\
\hline Infectious diseases (001-139) & 3 & $1.28(0.26-3.75)$ \\
\hline All cancers $(140-209)$ & 67 & $0.58(0.45-0.72)$ \\
\hline Mouth $(140-149)$ & 1 & $0.18(0.00-1.01)$ \\
\hline Digestive $(150-159)$ & 22 & $0.70(0.44-1.06)$ \\
\hline Pulmonary (162) & 26 & $0.56(0.37-0.82)$ \\
\hline Melanoma (172) & 2 & $2.00(0 \cdot 24-7 \cdot 22)$ \\
\hline & & $\begin{array}{l}3.00(0.62-8.77) \\
0.37(0.08-1.07)\end{array}$ \\
\hline $\begin{array}{l}\text { Genitourinary }(1 / 9-189) \\
\text { Eye, brain }(190-192)\end{array}$ & $2^{3}$ & $\begin{array}{l}0.37(0.08-1.07) \\
0.47(0.06-1.70)\end{array}$ \\
\hline Other (193-199) & 4 & $0.80(0.22-2.06)$ \\
\hline \multicolumn{3}{|l|}{ Lymphatic, haematopoietic } \\
\hline & 7 & $0.73(0.29-1.50)$ \\
\hline Endocrine diseases (240-279) & 3 & $0.40(0 \cdot 08-1 \cdot 16)$ \\
\hline Blood diseases $(280-289)$ & 1 & $1.69(0.04-9.44)$ \\
\hline \multicolumn{3}{|l|}{ Nervous system diseases } \\
\hline$(320-389)$ & 1 & $0.23(0.01-1 \cdot 26)$ \\
\hline Circulatory diseases $(390-459)$ & 108 & $0.63(0.52-0.76)$ \\
\hline Respiratory diseases $(460-519)$ & 7 & $0.41(0.16-0.84)$ \\
\hline Digestive diseases $(520-579)$ & 17 & $0.62(0.36-0.99)$ \\
\hline Genitourinary diseases $(580-629)$ & 1 & $0.37(0.01-2.08)$ \\
\hline Other diseases $(630-799)$ & 5 & $0.48(0 \cdot 16-1 \cdot 13)$ \\
\hline Accidents (800-999) & 18 & $0.42(0.25-0.67)$ \\
\hline
\end{tabular}

†Including one melanoma death miscoded as a primary pulmonary melanoma.

Vital status of each worker was first assessed using the company records, then through the Quebec Pension Plan (Regie des Rentes du Quebec) and finally through the Canadian Mortality Data Base.

The date, cause, and code of death (according to the 8th and 9th revision of the International Classification of Diseases (ICD $)^{2122}$ of each worker identified as deceased between 1976 and 1983 were obtained from the different Canadian provincial registries where the death occurred. Death certificates were not available for three workers who were excluded from the analysis.

Observed numbers of deaths among the workers were compared with those expected and $95 \%$ confidence intervals $(95 \% \mathrm{CIs})$ were calculated. ${ }^{23}$

\section{Results}

The cohort under study comprised 9590 workers of whom $75 \%$ were men. At the end of 1983,9180 workers were alive, 261 were dead, and $149(1.5 \%)$ were not traced. Men and women contributed 50274.4 and 17688.9 person-years respectively.

Among men, the SMR for all causes of death was $0 \cdot 57$. For all cancers, circulatory, respiratory, and digestive diseases, and accidents, SMRs were all low and significantly in deficit $(p<0.05)$. Two deaths occurred from MMS (SMR $=2 \cdot 00$ ). A third, which was an MMS with pulmonary metastasis, was miscoded on the death certificate as a primary pulmonary melanoma (SMR $=3.00 ; p=0.08)$ (table 1$)$.

For women, only SMRs for all causes of death, circulatory diseases, and accidents were significantly
Table 2 Standardised mortality ratios (SMRs) and $95 \%$ CIs in a telecommunications industry 1976-1983; female workers

\begin{tabular}{|c|c|c|}
\hline Cause of death & $\begin{array}{l}\text { Observed } \\
\text { deaths }\end{array}$ & $S M R(95 \% C I)$ \\
\hline $\begin{array}{l}\text { All (000-999) } \\
\text { Infectious diseases (001-139) } \\
\text { All cancers }(140-209) \\
\text { Digestive }(150-159) \\
\text { Pulmonary }(162) \\
\text { Bone, breast }(170-171,173-178) \\
\text { Melanoma }(172) \\
\text { Genitourinary }(179-189) \\
\text { Other (193-199) } \\
\text { Circulatory diseases (390-459) } \\
\text { Respiratory diseases }(460-519) \\
\text { Digestive diseases }(520-579) \\
\text { Accidents (800-999) }\end{array}$ & $\begin{array}{r}27 \\
1 \\
17 \\
5 \\
4 \\
5 \\
1 \\
1 \\
1 \\
6 \\
1 \\
1 \\
1\end{array}$ & $\begin{array}{l}0.56(0.37-0.82) \\
3.92(0.10-21.84) \\
0.87(0.50-1.39) \\
1.22(0.40-2.85) \\
1.54(0.42-3.95) \\
0.86(0.28-2.00) \\
4.81(0.12-26.78) \\
0.31(0.01-1.74) \\
1.16(0.03-6.48) \\
0.45(0.17-0.98) \\
0.60(0.02-3.36) \\
0.41(0.01-2.30) \\
0.16(0.00-0.92)\end{array}$ \\
\hline
\end{tabular}

lower than unity. The SMRs were high for infectious diseases $(n=1)$ and various types of cancer (digestive, pulmonary, and other) without reaching statistical significance. Only one death occurred from MMS (SMR $=4.81 ; 95 \%$ CI 0.12-26.78) (table 2).

For MMS, SMRs were calculated according to latency defined as the time between date of hire and date of death or censoring.

Among men with a latency period of 0-19 years, one death was observed. The SMR was 4.72 and was not significant (NS). Including the miscoded death would have raised the SMR significantly to 9.43 (95\% CI 1.14-34.06). Among men with a latency period of $\geqslant 20$ years $(n=1)$, the SMR was 1.28 (NS). Among women, the only death found was in the 0-19 year latency group. The SMR was 12.05 (NS) and the $95 \%$ CI was large (table 3 ).

\section{Discussion}

Two main results accrue from our present study. Firstly, the SMRs for all causes of death for workers of both sexes were surprisingly low. In a review of mortality studies, Carpenter noted that SMRs in cohorts of workers were usually around $0 \cdot 9 .{ }^{24}$ In our study the SMRs were 0.57 for men and 0.56 for women. The results were also analysed with two

Table 3 Standardised mortality ratios (SMRs) and 95\% CIs for malignant melanoma of the skin by sex and latency; workers of a telecommunications industry 1976-1983

\begin{tabular}{|c|c|c|c|}
\hline \multirow[b]{2}{*}{ Latency } & \multicolumn{2}{|l|}{ Deaths } & \multirow[b]{2}{*}{$S M R(95 \% C I)$} \\
\hline & Observed & Expected & \\
\hline $\begin{array}{l}\text { Men: } \\
<20 \text { years } \\
\geqslant 20 \text { years }\end{array}$ & $\begin{array}{l}1 \\
2 \star \\
1\end{array}$ & $\begin{array}{l}0.21 \\
0 \cdot 21 \\
0.78\end{array}$ & $\begin{array}{l}4.72(0.12-26.27) \\
9 \cdot 43(1 \cdot 14-34.06) \\
1.28(0.03-7 \cdot 11)\end{array}$ \\
\hline $\begin{array}{l}\text { Women: } \\
<20 \text { years } \\
\geqslant 20 \text { years }\end{array}$ & 1 & $\begin{array}{l}0.08 \\
0.13\end{array}$ & $\underline{12}^{1-05}(\underset{(-)}{(0.03-67 \cdot 11)}$ \\
\hline
\end{tabular}

^Including one melanoma death miscoded as a primary pulmonary melanoma. 
other reference populations: the population of the province of Quebec and the population of Canada. The results remained the same. In a separate investigation, actuaries have found that the lifespan of these workers was greater than most other groups of pensioners and have suggested to the company that pension contributions be increased.

There appears to be a strong healthy worker effect in our cohort. ${ }^{25}$ In fact, workers of the company studied are skilled and have good salaries compared with other workers in the Montreal area.

The duration of follow up (eight years) was determined by practical considerations. This comparatively short period could also have contributed to the low SMRs. ${ }^{26} 27$

The second result worth mentioning is that the workers showed higher but not statistically significant SMRs for MMS. This may be explained by two limitations of the study-namely, the short duration of follow up and the good five year survival for MMS in Canada; the five year survival from $1974-78$, was $84 \%$ for women and $73 \%$ for men. ${ }^{28}$

The high value of the SMRs may be explained by non-occupational factors. Skilled workers of the company may have adopted the habits of higher socioeconomic groups who are at higher risk of developing MMS. ${ }^{5}$

Even if the SMRs were high, the increased risk appeared in the 0-19 year latency group. Adding the miscoded case gives a significant excess $(\mathrm{SMR}=9 \cdot 43 ; 95 \%$ CI 1.14-34.06) (table 3). On the death certificate the hand-written cause of death of this additional case was "pulmonary melan." (for melanoma) or "pulmonary metas." (for metastasis), which was read by the nosologist as a primary pulmonary melanoma. This primary cancer is a very rare disease. Since 1888 , only 20 cases have been published. ${ }^{29}$ The case had been identified as an MMS in our first incidence study. ${ }^{1}$ So we are confident that this man had in fact an MMS.

An increased risk of MMS in the 0-19 year latency period was also seen in our first incidence study. ${ }^{1}$ This observation may argue against an occupational risk factor for MMS knowing that occupational cancers are usually seen after a long latency period..$^{30}$ It can be argued that melanoma may develop in a shorter time because of the synergistic effect of two factors such as exposure to sun, a possible promoting factor of MMS, ${ }^{31}$ and occupational exposure. ${ }^{32}$ Another study conducted in an Italian aircraft industry also showed an excess of MMS with a short latency period. ${ }^{15}$

Three other studies are of interest. One conducted in the electronics industry showed an increased risk of MMS of $1.35\left(95 \%\right.$ CI 1.05-1.76). ${ }^{33}$ A study conducted among workers in the telecommunications industry showed a standardised morbidity ratio for melanoma of $2.6(95 \%$ CI 1.3-4.5). The risk increased to 3.9 (95\% CI 1.4-8.5), however, among solderers. ${ }^{34}$ The third, a mortality study in a cohort of engineers in Sweden, gave an SMR for melanoma of $3.2(95 \%$ CI $0 \cdot 7-9 \cdot 4)$. Among the three deceased engineers, one had worked in telecommunications and the other two had worked in power transmission. ${ }^{35}$

For this study, we did not have access to information on exposures and occupational histories. We do know that PVC and PCBs were used in the plants. Also, some of the workers were involved in soldering. At this stage, it was not possible to identify possible interactions or associations between these exposures.

Secondary results were found among women. They showed SMRs higher than one for digestive, pulmonary, and other cancers that had no a priori relation with work. Can it be associated with specific exposures of women or to different life styles of these working women (for example, more cigarette smoking or more alcohol drinking) compared with the general population?

The excess (NS) of death from infectious diseases among men was also difficult to interpret. Two out of the three observed deaths occurred with underlying cancers (one lymphoma and one glioblastoma).

In conclusion, the cohort under investigation experienced a statistically significant excess of MMS in the incidence study, ${ }^{1}$ which was not repeated in the mortality study. The lack of information on work histories made it impossible to establish a link between MMS and occupational exposure. We are now carrying out a case-control study including incident and deceased cases to investigate further the possible associations with exposure at work.

We thank Dr Benedict Armstrong, McGill University, for his helpful advice on statistical procedures.

Requests for reprints to: Dr L DeGuire, Department of Community Health, Sacre-Coeur Hospital, 5945 Gouin West, Suite 200, Montreal, Quebec, Canada H4J 1 E5.

1 DeGuire L, Theriault G, Iturra H, Provencher S, Cyr D, Case BW. Increased incidence of malignant melanoma of the skin in workers in a telecommunications industry. $\mathrm{Br} J$ Ind $\mathrm{Med}$ 1988;45:824-8.

2 Elwood JM, Gallagher RP, Hill GB, Pearson JCG. Cutaneous melanoma in relation to intermittent and constant sun exposure. The Western Canada Melanoma Study. Int J Cancer 1985;35:427-33.

3 Elwood JM, Gallagher RP, Davison J, Hill GB. Sunburn, suntan and the risk of cutaneous malignant melanoma. The Western Canada Melanoma Study. Br J Cancer 1985;51: 543-9.

4 Evans RD, Kopf AW, Lew RA, et al. Risk factors for the development of malignant melanoma. I. Review of casecontrol studies. J Dermatol Surg Oncol 1988;14:393-408.

5 Lee JAH, Strickland D. Malignant melanoma: social status and outdoor work. Br J Cancer 1980;41:757-63.

6 Vagero D, Persson G. Risk, survival and trends of malignant melanoma among white and blue collar workers in Sweden. Soc Sci Med 1984;19:475-8. 
7 Beral V, Robinson N. The relationship of malignant melanoma, basal and squamous skin cancers to indoor and outdoor work. Br J Cancer 1981;44:886-91.

8 Storetvedt Heldaas S, Langard SL, Andersen A. Incidence of cancer among vinyl chloride and polyvinyl chloride workers. Br J Ind Med 1984;41:25-30.

9 Storetvedt Heldaas S, Andersen SL. Incidence of cancer among vinyl chloride and polyvinyl chloride workers: further evidence for an association with malignant melanoma. $\mathrm{Br} J$ Ind Med 1987;44:278-80.

10 Bahn AK, Rosenwaike I, Herrmann N, Grover P, Stellman J O'Leary K. Letter: Melanoma after exposure to PCB's. $N$ Engl J Med 1976;295:450.

11 Armstrong BK, McNulty JC, Levitt LJ, Williams KA, Hobbs MST. Mortality in gold and coal miners in Western Australia with special reference to lung cancer. $\mathrm{Br} J$ Ind Med 1979;36:199-205.

12 Blair A, Hayes HM. Cancer and other causes of death among US veterinarians, 1966-1967. Int J Cancer 1980;25:181-5.

13 Wright WE, Peters JM, Mack TM. Organic chemicals and malignant melanoma. Am J Ind Med 1983;44:577-81.

14 Austin DF, Reynolds PJ, Snyder MA, Biggs MW, Stubbs HA. Malignant melanoma among employees of Lawrence Livermore national laboratory. Lancet 1981;ii:712-6.

15 Costa G, Merletti F, Segnan N. A mortality cohort study in a north Italian aircraft factory. Br J Ind Med 1989;46:738-43.

16 Monson RR. Analysis of relative survival and proportional mortality. Comput Biomed Res 1975;7:325-32.

171976 Census of Canada. Population: geographic distributions. Reference maps. Statistics Canada. Catalogue 92-811 (bulletin 1.12).

181976 Census of Canada. Population: demographic characteristics. Five-year age groups. Statistics Canada. Catalogue 92-823 (bulletin 2.4).

191981 Census of Canada. Census metropolitan areas and census agglomerations. Reference maps. Statistics Canada. Catalogue 99-906.

201981 Census of Canada. Population, occupied private dwellings, private households, census families in private households. Selected characteristics. Quebec. Statistics Canada. Catalogue 93-917 (vol 2 provincial series).

21 World Health Organisation. International classification of diseases, injuries and causes of death. Vol I and II. 8th revision. Geneva: WHO, 1969.

22 World Health Organisation. International classification of dis- eases, injuries and causes of death. Vol I and II. 9th revision. Geneva: WHO, 1977.

23 Breslow NE, Day NE. Statistical methods in cancer research Vol II. The design and analysis of cohort studies. Lyon: International Agency for Research on Cancer, 1987. (IARC sci publ No 82).

24 Carpenter LM. Some observations on the healthy worker effect. Br J Ind Med 1987;44:289-91. (Editorial.)

25 Fox AJ, Collier PF. Low mortality rates in industrial cohort studies due to selection for work and survival in the industry. British Journal of Preventative and Social Medicine 1976;30:225-30.

26 Pearce N, Checkoway $\mathrm{H}$, Shy C. Time-related factors as potential confounders and effect modifiers in studies based on an occupational cohort. Scand $J$ Work Environ Health 1986;12:97-107.

27 Koskela RS, Jarvinen E, Kolari PJ. Effect of cohort definition and follow-up length on occupational mortality rates. Scand $J$ Work Environ Health 1984;10:311-6.

28 National Cancer Institute of Canada. Canadian cancer statistics 1989. Toronto: National Cancer Institute of Canada, 1989.

29 Bagwell SP, Flynn SD, Cox PM, Davison JA. Primary malignant melanoma of the lung. Am Rev Respir Dis 1989;139: 1543-7.

30 Doll R, Peto R. The causes of cancer: quantitative estimates of avoidable risks of cancer in the United States today. $J$ Nat Cancer Inst 1981;66:1193-308.

31 Elwood JM, Hislop TG. Solar radiation in the etiology of cutaneous malignant melanoma in Caucasians. National Cancer Institute Monographs 1982;62:167-71.

32 Morpurgo G, Maggini $M$. A hypothesis on the etiology of malignant melanoma: the role of chemicals interfering with melanin synthesis. European Journal of Cancer and Clinical Oncology 1987;23:1213-5.

33 Vagero $\mathrm{D}$, Olin $\mathrm{R}$. Incidence of cancer in the electronics industry: using the new Swedish cancer environment registry as a screening instrument. Br J Ind Med 1983;40:188-92.

34 Vagero D, Ahlbom A, Olin R, Saklstem S. Cancer morbidity among workers in the telecommunications industry. $\mathrm{Br} J$ Ind Med 1985;42:191-5.

35 Olin R, Vagero D, Ahlbom A. Mortality experience of electrical engineers. $\mathrm{Br} J$ Ind $\mathrm{Med}$ 1985;42:211-2.

Accepted 16 December 1991 